\title{
Outcomes of a hybrid approach of percutaneous coronary intervention followed by minimally invasive aortic valve replacement
}

\author{
Orlando Santana ${ }^{1}$, Steve Xydas ${ }^{2}$, Roy F. Williams ${ }^{2}$, Angelo LaPietra ${ }^{2}$, Maurice Mawad ${ }^{2}$, Gerald P. Rosen ${ }^{3}$, \\ Nirat Beohar ${ }^{1}$, Christos G. Mihos ${ }^{4}$ \\ ${ }^{1}$ The Columbia University Division of Cardiology, at the Mount Sinai Heart Institute, Miami Beach, FL, USA; ${ }^{2}$ The Division of Cardiac Surgery, \\ Mount Sinai Heart Institute, Miami Beach, FL, USA; ${ }^{3}$ The Department of Anesthesia, Mount Sinai Medical Center, Miami Beach, FL, USA; \\ ${ }^{4}$ Cardiac Ultrasound Laboratory, Massachusetts General Hospital, Harvard Medical School, Boston, MA, USA \\ Contributions: (I) Conception and design: O Santana, CG Mihos, N Beohar; (II) Administrative support: None; (III) Provision of study materials or \\ patients: None; (IV) Collection and assembly of data: O Santana; (V) Data analysis and interpretation: O Santana, S Xydas, RF Williams, A LaPietra, \\ M Mawad, GP Rosen, N Beohar; (VI) Manuscript writing: All authors; (VII) Final approval of manuscript: All authors. \\ Correspondence to: Orlando Santana, MD. Director, Echocardiography Laboratory, Columbia University Division of Cardiology, Mount Sinai Heart \\ Institute, 4300 Alton Road, Miami Beach, FL 33140, USA. Email: osantana@msmc.com.
}

Background: In patients requiring coronary revascularization and aortic valve replacement, a combined approach of percutaneous coronary intervention followed by minimally invasive aortic valve replacement may be a viable treatment strategy.

Methods: The outcomes of 123 consecutive patients with significant coronary artery and aortic valve disease, who underwent percutaneous coronary intervention followed by elective minimally invasive aortic valve replacement between February 2009 and April 2014, were retrospectively evaluated.

Results: The cohort consisted of 80 males and 43 females, with a mean age of $75.7 \pm 8.1$ years. Drug-eluting stents were used in $69.9 \%$ of the patients, and $64.2 \%$ were on dual anti-platelet therapy at the time of aortic valve replacement. Within a median of 39 days (IQR 21-64), 83.7\% of the patients underwent primary and $16.3 \%$ underwent re-operative minimally invasive aortic valve replacement. Post-operatively, there was 1 $(0.8 \%)$ cerebrovascular accident, 1 patient $(0.8 \%)$ required a re-operation due to bleeding, and $2(1.6 \%)$ developed acute kidney injury. Thirty-day mortality occurred in $2(1.6 \%)$ patients. Follow-up was available for all of the patients, and at a mean follow-up period of $14.3 \pm 12.5$ months, 4 (3.3\%) had an acute coronary syndrome, and $1(0.8 \%)$ required a repeat target vessel revascularization. The actuarial survival rate at $1-$ and 3 -year was $92.7 \%$ and $89.4 \%$, respectively.

Conclusions: In a select group of patients with coronary artery and aortic valve disease, a combined approach of percutaneous coronary intervention followed by minimally invasive aortic valve replacement can be safely performed with excellent short-term and midterm outcomes.

Keywords: Coronary artery disease; aortic valve disease; percutaneous coronary intervention; aortic valve replacement; minimally invasive surgery

Submitted Mar 21, 2017. Accepted for publication Apr 10, 2017.

doi: $10.21037 /$ jtd.2017.04.28

View this article at: http://dx.doi.org/10.21037/jtd.2017.04.28 


\section{Introduction}

Minimally invasive valve surgery (MIVS), by its less traumatic nature, has been demonstrated to significantly reduce blood loss, morbidity, post-operative pain, intensive care unit and hospital lengths of stay, and healthcare expenditures, while enhancing post-operative recovery, when compared with a traditional median sternotomy approach (1-3). It may be that these benefits are increased in patients with more comorbidity, or those undergoing higher-risk procedures (4-8).

In patients with concomitant coronary artery and valvular disease, the performance of percutaneous coronary intervention (PCI) permits the use of MIVS (PCI + MIVS). The goal of utilizing an approach of PCI + MIVS is the avoidance of a standard median sternotomy required to perform coronary artery bypass (CABG) and valve surgery, which potentially reduces the operative risk of the patient. This concept of reducing the total risk of a single major operation to the less invasive procedures of PCI+MIVS has been applied in clinical practice and reported by various groups (9-16).

When compared with a standard median sternotomy coronary artery bypass and valve surgery, an approach of PCI + MIVS has been demonstrated to significantly reduce post-operative complications, and shorten the intensive care unit and hospital lengths of stay (12). Herein, we present our experience utilizing this method in a consecutive series of patients with coronary artery disease requiring isolated aortic valve replacement.

\section{Methods}

After obtaining approval from the Mount Sinai Medical Center Institutional Review Board, the outcomes of patients with concomitant coronary and aortic valve disease that underwent PCI + MIVS, from February 2009 and April 2014, were retrospectively evaluated. The baseline characteristics, echocardiographic, PCI, and operative variables, and postoperative outcomes were reviewed. If a patient was planned to have PCI + MIVS, but required conversion to median sternotomy, that patient was included in the study to conform with an intention-to-treat analysis. All patients had an outpatient follow-up visit 30 days after surgery. Thereafter, follow-up data were obtained by accessing the local electronic health records, office follow-up visits, and by a follow-up telephone survey every 6 months using an Institutional Review Board approved questionnaire. Additionally, vital status was assessed using the Social Security Death Index.
The variables and outcome definitions were selected based on the Society of Thoracic Surgeons (STS) Database version 2.73 .

In all patients, the coronary anatomy and valvular lesions were documented by diagnostic catheterization and transthoracic and/or transesophageal echocardiography, respectively. The PCI consisted of angioplasty with or without stenting of all the angiographically or hemodynamically significant lesions in the native vessels and/or bypass grafts. In all the patients, a loading dose of $600 \mathrm{mg}$ of clopidogrel and $325 \mathrm{mg}$ of aspirin was administered prior to stent placement, followed by clopidogrel $75 \mathrm{mg}$ daily and aspirin 81 to $325 \mathrm{mg}$ daily, thereafter. The pre-operative anti-platelet regimen was resumed on day one or two post-operatively after MIVS. Our surgical approach has been described previously, and consists of a right anterior thoracotomy (12).

\section{Statistical analysis}

The patient demographics and operative data were expressed as the mean \pm 1 standard deviation (SD), or median and interquartile range (IQR, 25-75\%), as appropriate. A Kaplan-Meier analysis was performed to estimate actuarial survival after PCI+MIVS. The statistical analyses were conducted using Statistical Package for Social Sciences, version 21 (SPSS Inc., Chicago, IL).

\section{Results}

There were 123 patients identified who underwent PCI + MIVS, of which 80 (65\%) were male and 43 (35\%) were female, with a mean age of $75.7 \pm 8.1$ years. The median left ventricular ejection fraction and preoperative creatinine were $60 \%$ (IQR, 55-65) and $1.0 \mathrm{mg} / \mathrm{dl}$ (IQR, 0.9-1.3), respectively. There were 20 patients $(16.3 \%)$ with a history of previous cardiac surgery, of which previous coronary artery bypass graft surgery had been performed in $12(9.8 \%)$ patients, previous valve surgery in $6(4.9 \%)$, and $2(1.6 \%)$ had previous combined coronary artery bypass graft surgery and valve surgery (Table 1).

Single and multi-vessel PCI was performed in 98 (79.7\%) and $25(20.3 \%)$ patients, respectively. The majority of interventions were performed in the native coronary arteries, with the most commonly treated vessels being the left anterior descending coronary artery in $59(48 \%)$ patients, and the right coronary artery in $41(33.3 \%)$. Drug-eluting stents were placed in $86(69.9 \%)$ patients, 
Table 1 Patients baseline characteristics

\begin{tabular}{lc}
\hline Variable & $\mathrm{N}=123$ \\
\hline Age (years, mean $\pm \mathrm{SD})$ & $75.7 \pm 8.1$ \\
Males & $80(65 \%)$ \\
Hypertension & $118(95.9 \%)$ \\
Diabetes mellitus & $48(39 \%)$ \\
Dyslipidemia & $111(90.2 \%)$ \\
Cerebrovascular disease & $27(22 \%)$ \\
Peripheral vascular disease & $27(22 \%)$ \\
Congestive heart failure & $17(13.8 \%)$ \\
Left ventricular ejection fraction (\%, median, IQR) & $60[55-65]$ \\
Preoperative creatinine (mg/dl, median, IQR) & $1.0[0.9-1.3]$ \\
Body mass index (kg/m ${ }^{2}$, mean \pm SD) & $29 \pm 5$ \\
Prior coronary artery bypass graft surgery & $12(9.8 \%)$ \\
Prior valve surgery & $6(4.9 \%)$ \\
Prior combined coronary bypass graft surgery & $2(1.6 \%)$ \\
and valve surgery & $104(84.6 \%)$ \\
Pre-operative angiotensin converting enzyme & $29(23.6 \%)$ \\
inhibitor & $98(79.7 \%)$ \\
Pre-operative beta blocker & $79(64.2 \%)$ \\
Pre-operative aspirin & \\
Pre-operative clopidogrel & $79(64.2 \%)$ \\
Pre-operative dual anti-platelet therapy & \\
\hline SD, & \\
\hline
\end{tabular}

$\mathrm{SD}$, standard deviation; IQR, interquartile range.

bare metal stents in $35(28.5 \%)$, and balloon angioplasty only was performed in $2(1.6 \%)$, respectively. All patients were clinically stable for both the PCI and valve surgery. The median time between the PCI and MIVS was 39 days (IQR, 21-64). At the time of valve surgery, 79 (64.2\%) patients were on dual anti-platelet therapy (Table 2).

The median aortic cross-clamp and cardiopulmonary bypass times were 81 (IQR, 70-97) and 109 minutes (IQR, 92-131), respectively. The median number of packed red blood cells transfused intra-operatively was 1 unit (IQR, 0-2). Conversion to median sternotomy was performed in 1 patient $(0.8 \%)$, due to poor surgical field exposure, and is included in the present intention to treat analysis (Table 3). The median intensive care unit length of stay was 44 hours (IQR, 26-71). Post-operative complications included $16(13 \%)$ patients with prolonged
Table 2 Percutaneous coronary intervention characteristics

\begin{tabular}{lc}
\hline Variable & $\mathrm{N}=123$ \\
\hline Number of stents (mean $\pm \mathrm{SD})$ & $1.4 \pm 0.7$ \\
Drug eluting stent & $86(69.9 \%)$ \\
Bare metal stent & $35(28.5 \%)$ \\
Plain balloon angioplasty & $2(1.6 \%)$ \\
Left anterior descending coronary artery & $59(48 \%)$ \\
Proximal left anterior descending coronary artery & $34(27.6 \%)$ \\
Left circumflex coronary artery & $40(32.5 \%)$ \\
Right coronary artery & $41(33.3 \%)$ \\
Ramus intermedius coronary artery & $1(0.8 \%)$ \\
Diagonal coronary artery & $7(5.7 \%)$ \\
Protected left main coronary artery & $3(2.4 \%)$ \\
Saphenous vein graft & $3(2.4 \%)$ \\
Single vessel percutaneous coronary intervention & $98(79.7 \%)$ \\
Two vessel percutaneous coronary intervention & $22(17.9 \%)$ \\
Three vessel percutaneous coronary intervention & $3(2.4 \%)$ \\
Time from percutaneous coronary intervention to & $39[21-64]$ \\
valve surgery (days, median, IQR) & \\
\hline SD, standard deviation; IQR, interquartile range. &
\end{tabular}

mechanical ventilation, 30 (24.4\%) with post-operative atrial fibrillation, $1(0.8 \%)$ with a cerebrovascular accident, $1(0.8 \%)$ with re-operation for bleeding, and $2(1.6 \%)$ with acute kidney injury. The median total hospital length of stay, which included the hospital days for the PCI interventions, was 7 days (IQR, 6-9). Thirty-day mortality occurred in $2(1.6 \%)$ patients (Table 4$)$.

Follow-up was available in $100 \%$ of the patients. At a mean follow-up of $14.3 \pm 12.5$ months, acute coronary syndrome occurred in $4(3.3 \%)$ of the patients, and $1(0.8 \%)$ patient required a repeat target vessel revascularization (Table 5). The actuarial survival rate at 1 and 3 years was $92.7 \%$ and $89.4 \%$, respectively.

\section{Discussion}

The prevalence of significant coronary artery disease is estimated to be $25 \%$ to $50 \%$ in patients with operable valvular heart disease, for which the most common treatment is a combined CABG and valve surgery via a median sternotomy $(17,18)$. In patients requiring aortic valve 
Table 3 Operative characteristics

\begin{tabular}{lc}
\hline Variable & $\mathrm{N}=123$ \\
\hline Femoral artery cannulation & $107(87 \%)$ \\
Axillary artery cannulation & $6(4.9 \%)$ \\
Central cannulation & $10(8.1 \%)$ \\
$\begin{array}{l}\text { Aortic cross-clamp time } \\
\text { (minutes, median, IQR) }\end{array}$ & $81[70-97]$ \\
$\begin{array}{l}\text { Cardiopulmonary bypass time } \\
\text { (minutes, median, IQR) }\end{array}$ & $109[92-131]$ \\
Patients requiring intra-operative & \\
packed red blood cells transfusion & $56(45.5 \%)$ \\
Intra-operative packed red blood cells & \\
(units, median, IQR) & $1[0-2]$ \\
Conversion to median sternotomy & $1(0.8 \%)$ \\
\hline IQR, interquartile range. &
\end{tabular}

Table 4 Post-operative outcomes

\begin{tabular}{lc}
\hline Variable & $\mathrm{N}=123$ \\
\hline $\begin{array}{l}\text { Intensive care unit length of stay } \\
\text { (hours, median, IQR) }\end{array}$ & $44[26-71]$ \\
$\begin{array}{l}\text { Patients requiring post-operative } \\
\text { packed red blood cells }\end{array}$ & $41(33.3 \%)$ \\
$\begin{array}{l}\text { Post-operative packed red blood cells } \\
\text { (units, median, IQR) }\end{array}$ & $0[0-1]$ \\
Prolonged mechanical ventilation & \\
Re-intubation & $16(13 \%)$ \\
Atrial fibrillation & $5(4.1 \%)$ \\
Cerebrovascular accident & $30(24.4 \%)$ \\
Re-operation for bleeding & $1(0.8 \%)$ \\
Acute kidney injury & $1(0.8 \%)$ \\
Myocardial infarction & $2(1.6 \%)$ \\
Total PCl and MIVS hospital length & 0 \\
of stay (days, median, IQR) & $7[6-9]$ \\
Thirty-day mortality & $2(1.6 \%)$ \\
\hline
\end{tabular}

$\mathrm{IQR}$, interquartile range; $\mathrm{PCI}$, percutaneous coronary intervention; MIVS, minimally invasive valve surgery.

surgery, the addition of CABG to aortic valve replacement increases the operative mortality risk from 2.1 to $3.9 \%$, and significantly prolongs the hospital length of stay $(19,20)$. For individuals undergoing re-operative valve surgery, sternal re-entry via a median sternotomy more than doubles the risk
Table 5 Follow-up outcomes

\begin{tabular}{ll}
\hline Variable & $\mathrm{N}=123$ \\
\hline Time to follow-up (months, mean $\pm \mathrm{SD})$ & $14.3 \pm 13$ \\
Acute coronary syndrome & $4(3.3 \%)$ \\
Target vessel revascularization & $1(0.8 \%)$ \\
Cerebrovascular accident & $4(3.3 \%)$ \\
Hospitalization due to congestive heart failure, & $8(6.5 \%)$ \\
acute coronary syndrome, or bleeding & \\
\hline
\end{tabular}

$\mathrm{SD}$, standard deviation.

of peri-operative morbidity, due to thoracic adhesions, injury to patent coronary bypass grafts, and challenging surgical field exposure, amongst other factors $(21,22)$. As a result, a combined approach of PCI + MIVS has been introduced as a possible alternative treatment strategy.

The present study demonstrates that PCI+MIVS for coronary artery disease and aortic valve replacement can be performed with a low peri-operative morbidity and thirty-day mortality, and a good follow-up survival rate. It is important to note that despite having $64.2 \%$ of patients on dual anti-platelet therapy at the time of MIVS, the bleeding complications were low, with the median intraoperative blood transfusion requirement being 1 unit, and only $1(0.8 \%)$ patient requiring re-operation for bleeding. The post-operative complications were low despite having $20.3 \%$ of the patients undergoing multivessel PCI, and $16.3 \%$ undergoing re-operative valve surgery.

The combined approach of PCI with valve surgery was first investigated in 2005 by Byrne et al, in a retrospective study of 26 patients, 24 (92.3\%) of whom underwent PCI for acute coronary syndromes, and 2 (7.7\%) for re-operative valve surgery (9). The patients underwent aortic or mitral valve surgery using a minimally invasive approach in $8(30.8 \%)$, and a traditional median sternotomy in the rest. The operative mortality was $3.8 \%$, which was much lower than the predicted mortality of $22 \%$. A subsequent observational study of 18 patients with coronary artery disease and severe aortic valve stenosis reported on a strategy of PCI performed on the day of or the evening prior to a scheduled minimally invasive aortic valve replacement (10). There was one non-cardiac in-hospital death, and no late mortality at a mean follow-up of 19 months. Some authors suggest that the benefits obtained from staging PCI and valve surgery are greater when a minimally invasive technique is utilized, in patients with an acute coronary syndrome, in those that have poor 
conduit or target-vessel quality, have left ventricular systolic dysfunction, and/or are undergoing re-operative cardiac surgery (23-25). With regards to MIVS, direct comparisons with combined CABG and valve surgery have associated PCI+MIVS with fewer adverse events and a faster postoperative recovery (12).

There are important limitations to the present data that should be considered. Firstly, this was a single-center, retrospective study, which confers an inherent selection bias. Secondly, the mean follow-up was approximately 1 year, and cannot be extrapolated to represent mid or long-term outcomes of a PCI + MIVS approach. Thirdly, the MIVS approach utilized in this series of patients was a right anterior thoracotomy, and these results may not be representative of outcomes achieved via alternative techniques. Finally, the occurrence of acute coronary syndrome was low with $4(3.3 \%)$ patients presenting as such, of which $1(0.8 \%)$ required a repeat target vessel revascularization. In the three-year follow-up of the Synergy between PCI with Taxus and Cardiac Surgery (SYNTAX) trial, which randomized patients with multi-vessel or left main coronary artery disease to undergo PCI with drugeluting stents or CABG, the incidence of myocardial infarction and required repeat revascularization in the PCI arm was $7.1 \%$ and $19.7 \%$, respectively, and occurred significantly more often than in patients randomized to CABG $(26,27)$. Placed within this context, the outcomes presented herein must be cautiously interpreted as representing a group of patients carefully selected for PCI + MIVS based on suitable coronary anatomy, of which the majority underwent single-vessel PCI. Additionally, the impact of the type and generation of stent implanted, the complexity of the coronary lesion(s) treated, and the lack of a comparable CABG group, further limits the generalizability of these results.

In conclusion, for a select group of patients with coronary artery and aortic valve disease, a combined approach of PCI followed by minimally invasive aortic valve replacement can be safely performed with satisfactory outcomes. Prospective trials with long term follow-up comparing PCI+MIVS with combined CABG and valve surgery, as well as staged PCI followed by transcatheter aortic valve replacement, are paramount in identifying the patient groups who would most benefit from these respective treatment strategies.

\section{Acknowledgements}

None.

\section{Footnote}

Conflicts of Interest: The authors have no conflicts of interest to declare.

Ethical Statement: The study was approved by institutional/ regional/national ethics committee/ethics board of Mount Sinai Medical Center and written informed consent was obtained from all patients.

\section{References}

1. Schmitto JD, Mokashi SA, Cohn LH. Minimally-invasive valve surgery. J Am Coll Cardiol 2010;56:455-62.

2. Cheng DC, Martin J, Lal A, et al. Minimally invasive versus conventional open mitral valve surgery: a metaanalysis and systematic review. Innovations (Phila) 2011;6:84-103.

3. Santana O, Larrauri-Reyes M, Zamora C, et al. Is a minimally invasive approach for mitral valve surgery more cost-effective than median sternotomy? Interact Cardiovasc Thorac Surg 2016;22:97-100.

4. Santana O, Reyna J, Grana R, et al. Outcomes of minimally invasive valve surgery versus standard sternotomy in obese patients undergoing isolated valve surgery. Ann Thorac Surg 2011;91:406-10.

5. Santana O, Reyna J, Benjo AM, et al. Outcomes of minimally invasive valve surgery in patients with chronic obstructive pulmonary disease. Eur J Cardiothorac Surg 2012;42:648-52.

6. Goldstone AB, Joseph Woo Y. Minimally invasive surgical treatment of valvular heart disease. Semin Thorac Cardiovasc Surg 2014;26:36-43.

7. Mihos CG, Santana O, Lamas GA, et al. Outcomes of right minithoracotomy mitral valve surgery in patients with previous sternotomy. Ann Thorac Surg 2011;91:1824-7.

8. Pineda AM, Santana O, Reyna J, et al. Outcomes of reoperative aortic valve replacement via right minithoracotomy versus median sternotomy. J Heart Valve Dis 2013;22:50-5.

9. Byrne JG, Leacche M, Unic D, et al. Staged initial percutaneous coronary intervention followed by valve surgery ("hybrid approach") for patients with complex coronary and valve disease. J Am Coll Cardiol 2005;45:14-8.

10. Brinster DR, Byrne M, Rogers CD, et al. Effectiveness of same day percutaneous coronary intervention followed by minimally invasive aortic valve replacement for aortic stenosis and moderate coronary disease ("hybrid 
approach"). Am J Cardiol 2006;98:1501-3.

11. Umakanthan R, Leacche $M$, Petracek MR, et al.

Combined PCI and minimally invasive heart valve surgery for high-risk patients. Curr Treat Options Cardiovasc Med 2009;11:492-8.

12. Santana O, Funk M, Zamora C, et al. Staged percutaneous coronary intervention and minimally invasive valve surgery: results of a hybrid approach to concomitant coronary and valvular disease. J Thorac Cardiovasc Surg 2012;144:634-9.

13. Santana O, Pineda AM, Cortes-Bergoderi M, et al. Hybrid approach of percutaneous coronary intervention followed by minimally invasive valve operations. Ann Thorac Surg 2014;97:2049-55.

14. George I, Nazif TM, Kalesan B, et al. Feasibility and early safety of Single-Stage hybrid coronary intervention and valvular cardiac surgery. Ann Thorac Surg 2015;99:2032-7.

15. Mihos CG, Santana O, Pineda AM, et al. Percutaneous coronary intervention followed by minimally invasive mitral valve surgery in ischemic mitral regurgitation. Innovations (Phila) 2015;10:394-7.

16. Pineda AM, Chandra R, Gowani SA, et al. Completeness of revascularization and its impact on the outcomes of a staged approach of percutaneous coronary intervention followed by minimally invasive valve surgery for patients with concomitant coronary artery and valvular heart disease. Catheter Cardiovasc Interv 2016;88:329-37.

17. Goel SS, Ige M, Tuzcu EM, et al. Severe aortic stenosis and coronary artery disease--implications for management in the transcatheter aortic valve replacement era: a comprehensive review. J Am Coll Cardiol 2013;62:1-10.

18. Emren ZY, Emren SV, Kılıçaslan B, et al. Evaluation of the prevalence of coronary artery disease in patients with valvular heart disease. J Cardiothorac Surg 2014;9:153.

19. Nowicki ER, Birkmeyer NJ, Weintraub RW, et al.

Cite this article as: Santana O, Xydas S, Williams RF, LaPietra A, Mawad M, Rosen GP, Beohar N, Mihos CG. Outcomes of a hybrid approach of percutaneous coronary intervention followed by minimally invasive aortic valve replacement. J Thorac Dis 2017;9(Suppl 7):S569-S574. doi: 10.21037/ jtd.2017.04.28
Multivariable prediction of in-hospital mortality associated with aortic and mitral valve surgery in Northern New England. Ann Thorac Surg 2004;77:1966-77.

20. D'agostino RS, Jacobs JP, Badhwar V, et al. The society of thoracic surgeons adult cardiac surgery database: 2017 update on outcomes and quality. Ann Thorac Surg 2017;103:18-24.

21. Balsam LB, Grossi EA, Greenhouse DG, et al. Reoperative valve surgery in the elderly: predictors of risk and longterm survival. Ann Thorac Surg 2010;90:1195-200; discussion 1201.

22. Dobrilovic N, Fingleton JG, Maslow A, et al. Midterm outcomes of patients undergoing aortic valve replacement after previous coronary artery bypass grafting. Eur J Cardiothorac Surg 2012;42:819-24; discussion 824-5.

23. Santana O, Singla S, Mihos CG, et al. Outcomes of a Combined Approach of Percutaneous Coronary Revascularization and Cardiac Valve Surgery. Innovations (Phila) 2017;12:4-8.

24. Byrne JG, Leacche M, Vaughan DE, et al. Hybrid cardiovascular procedures. JACC Cardiovasc Interv 2008;1:459-68.

25. Leacche M, Umakanthan R, Zhao DX, et al. Surgical update: hybrid procedures, do they have a role? Circ Cardiovasc Interv 2010;3:511-8.

26. Kappetein AP, Feldman TE, Mack MJ, et al. Comparison of coronary bypass surgery with drug-eluting stenting for the treatment of left main and/or three-vessel disease: 3 -year follow-up of the SYNTAX trial. Eur Heart J 2011;32:2125-34.

27. Parasca CA, Head SJ, Milojevic M, et al. Incidence, characteristics, predictors, and outcomes of repeat revascularization after percutaneous coronary intervention and coronary artery bypass grafting: the SYNTAX trial at 5 years. JACC Cardiovasc Interv 2016;9:2493-507. 